\section{Politics and public space: radical citizenship in} commemorative events

\section{| RESUMEN |}

En el presente texto se analizan algunas de las formas de manifestación que se desarrollan en fechas conmemorativas, bajo el supuesto de que muchas de estas formas han sido adoptadas en las manifestaciones políticas del año 20ll. Para esto se revisan algunas de estas formas de ocupación del espacio público, entendiéndolo como un espacio en pugna. También se propone entender a las manifestaciones políticas como expresiones de construcción de una ciudadanía radical. Ciudadana en tanto se constituye en la ocupación del espacio público y radical en tanto se define desde la pluralidad y el orgullo de quienes se manifiestan.

\section{| ABSTRACT |}

This paper will discuss some of the forms of demonstration developed in commemorative dates, under the assumption that many of them have been adopted at political demonstrations in 20II. In doing so, we review some of these forms of the occupation of public space, understanding them as a space of conflict. The paper also aims to understand the political demonstrations as expressions of a radical citizenship building. Citizenship because it is developed in the occupation of public space and radical because it is defined from the plurality and the pride of those who express themselves.

\title{
Política y espacio público: ciudadanía radical en manifestaciones conmemorativas
}

\section{INTRODUCCIÓN}

El año 2011 será recordado en todo el mundo como un año marcado por manifestaciones políticas en el espacio público de diferentes ciudades del mundo, manifestaciones sin precedentes en las últimas décadas, tanto por la masividad que han tenido como por su impacto mediático. La revolución árabe, las movilizaciones sociales en Europa contra el desempleo y los reajustes macroeconómicos, el reciente movimiento de los «indignados» en España y los EE. UU. y, por cierto, las manifestaciones en torno a la educación en Chile, dan cuenta de una excepcional vigencia del espacio público como espacio urbano de expresión política y ciudadana.

Aún cuando todavía es muy temprano para realizar un análisis más acabado sobre estas manifestaciones, cabe destacar que un elemento común a éstas ha sido la reivindicación de los fundamentos de la democracia y de la participación ciudadana. En un reciente análisis de prensa, Marcos Roitman (2011) plantea que estas manifestaciones serían el resultado de la acumulación de descontento respecto del sistema político y económico imperante, que tendría como uno de sus horizontes la recuperación de una ciudadanía inclusiva basada en la libertad y la democracia. "Las actuales movilizaciones son el resultado de un lento proceso donde se reúnen fuerzas, experiencias, y el malestar se organiza. Cuando se reivindica "democracia, libertad y justicia», y se protesta contra la corrupción de los partidos políticos, el poder omnímodo de banqueros y el capital financiero, las políiticas de ajustes, el paro juvenil, el sistema electoral, la privatización de la salud, la enseñanza o el calentamiento global, se desnudan sistemas políticos donde prima la injusticia, la desigualdad y la explotación» (Roitman 2011 , p. 5).

Una de las particularidades de este movimiento social es su carácter espacial, donde las calles y plazas de las ciudades se han convertido en parte constitutiva de estas manifestaciones. Como señala Roitman $(2011$, p. 5) «el descontento se hace visible, se exterioriza, el malestar aflora a la superficie. El resultado inmediato es la recuperación de los espacios públicos. Se toman las plazas, convirtiéndolas en fortines de ciudadanía». Para Roitman (2011), la ocupación del espacio público en las manifestaciones del año 2011 constituye la negación de un modelo de ciudad caracterizado por una ciudadanía pasiva sometida a lógicas de consumo, y su reemplazo por el ejercicio de una ciudadanía activa y crítica.

Psicólogo Universidad ARCIS. Magíster en Psicología Social Universidad Autónoma de Barcelona / Universidad ARCIS. Candidato a Doctor en Arquitectura y Estudios urbanos, Pontificia Universidad Católica de Chile. Académico Departamento de Psicología, Facultad de Ciencias Sociales, Universidad de Chile. 
Por otra parte, el sociólogo español Enrique Gil Calvo (2011) analiza las características de la ocupación del espacio público en las diferentes manifestaciones del año 2011 , principalmente en Europa y los países árabes. Una de las características principales de estas manifestaciones es el uso del espacio público como elemento fundamental de la puesta en escena de sus protestas y de las posibilidades de incidir en la opinión pública. Para este autor, esto implica «la construcción de una nueva realidad social a partir de la catarsis creada por la ocupación escénica del espacio público. Lo cual exige despertar el interés unánime de los medios mediante la suspensión extraordinaria del orden cotidiano habitual, pues sólo así se logra convertir en acontecimiento histórico lo que sin el refrendo mediático resultaría un acto privado y ficticio» (Enrique Gil Calvo 2011 s/p). Es decir, que la acción de los manifestantes solamente cobra sentido en relación a la producción y circulación de las imágenes que éstos son capaces de producir y difundir, lo cual implica una participación fundamental de los medios de comunicación. Así para el autor uno de los elementos que se destaca como común a estas distintas expresiones de descontento es «la compulsiva propensión a documentarlas con testimonios gráficos: los manifestantes se dedican sobre todo a fotografiarse a sí mismos participando en la manifestación, para poder colgar en sus redes sociales las pruebas gráficas de que ellos formaban parte del happening. De este modo, la fotografía consigue hacer real lo que de otro modo parecería una participación imaginaria. Así se produce una performance: una ejecución escénica que al ocupar el espacio público logra convertir en reales a las redes virtuales» (Enrique Gil Calvo 201 1, s/p).

El análisis de Gil Calvo permite reparar en un aspecto fundamental de cualquier manifestación en el espacio público, que es la dimensión visual implicada en salir a la calle: manifestarse supone ser visto por otros (Fernández y Hermansen, 2009). En la propuesta de Hanna Arendt (2005), el espacio público supone esta dimensión visual en la medida que define a este espacio como un espacio de aparición. «Todo lo que aparece en público puede verlo y oírlo todo el mundo y tiene la más amplia publicidad posible» (Arendt, 2005, p. 59).
Pero además de la dimensión visual de lo público, este espacio también supone el encuentro con otros. Como señala Arendt (2005, p. 61) «el término "público" significa el propio mundo, en cuanto es común a todos nosotros y diferenciado de nuestro lugar poseído privadamente en él». Lo común se entiende en relación al espacio compartido de la polis y aparece en la medida que hay un mundo e intereses compartidos, relativos a la vida en la ciudad. Sin embargo, lo común no implica una homogeneidad de puntos de vista, sino que por lo contrario conlleva una multiciplicidad de miradas. Por lo tanto, lo común también es el espacio de la diversidad. «Ser visto y oído por otros deriva su significado del hecho de que todos ven y oyen desde una posición diferente» (Arendt, 2005, p. 66).

En definitiva el espacio público es un espacio de aparición, caracterizado por el encuentro con otros y la posibilidad de ver, ser visto e interactuar con aquéllos. «La polis, propiamente hablando, no es la ciudad-estado en su situación física; es la organización de la gente tal como surge de actuar y hablar juntos (...) Se trata del espacio de aparición en el más amplio sentido de la palabra, es decir, el espacio donde yo aparezco ante otros como otros aparecen ante mí, donde los hombres no existen meramente como otras cosas vivas o inanimadas, sino que hacen su aparición de manera explícita» (Arendt, 2005, p. 221).

Las manifestaciones del año 2011 pueden considerarse como instancias políticas de aparición en el espacio público, aparición de diversos actores sociales que despliegan una serie de estrategias de visibilización que tienen como escenario el entorno urbano. El presente texto tiene como objetivo proponer que algunas de las estrategias de visibilización de los manifestantes en el espacio público, principalmente las relativas a la ocupación de ciertos sectores de la ciudad, tienen antecedentes históricos, entre los cuales se encuentran, en el caso chileno, manifestaciones conmemorativas que se han venido desarrollando durante los gobiernos posteriores a la dictadura militar. Específicamente hablamos del Día Internacional de la Mujer (08 de marzo), el Día Internacional del Trabajador (01 de mayo), el Día del Orgullo Gay (en Chile se conmemora el último sábado de septiembre), y la contraconmemoración del descubrimiento de América (12 de octubre).

En estas manifestaciones conmemorativas se han puesto en escena determinadas formas de manifestarse que han contribuido a configurar un imaginario de manifestación que ha sido retomado en otro tipo de manifestaciones como las estudiantiles. A partir de registros fotográficos de estas conmemoraciones obtenidos en el año 2008 se analizarán estas formas de manifestación y sus efectos en la construcción de un espacio público más activo, abierto y diverso. Finalmente, se propondrá que estas manifestaciones no solamente han contribuido a enriquecer las formas de uso del espacio público para manifestaciones políticas, sino que también han ido configurando lo que podríamos llamar una ciudadanía radical. Ciudadanía en el sentido de sujetos que se constituyen en ciudadanos mediante su presencia en el espacio público, y radical en tanto esta presencia está marcada por un creciente sentido de orgullo y empoderamiento de quienes salen a la calle a manifestarse.

\section{CONTEXTO URBANO DE APARICIÓN: EL ESPACIO PÚBLICO COMO ESPACIO EN PUGNA}

La aparición en el espacio público propia de las manifestaciones políticas supone la alteración de los modos cotidianos de aparición ante otros, en un contexto que Delgado (2007) ha definido como de visibilidad mutua generalizada. En la vida cotidiana de las ciudades la aparición ante otros está regulada por reglas y normas que permiten una interacción social basada en el anonimato y cierta desatención o distancia. Esta copresencia regida por normas precariamente estructuradas, en el sentido que se ven alteradas y reconfiguradas permanentemente como parte de los dinamismos propios de la vida urbana, se ven alteradas en las manifestaciones, ya que éstas generan un giro en esos modos de estar juntos. En este contexto la aparición apunta justamente a hacerse reconocible ante otros como sujeto específico, rompiendo con la lógica del anonimato y la desatención. La idea de hacerse reconocible ante otros, propuesta por Judith Butler (2009) a partir de los postulados de Arendt, parte de la base que existen sujetos que no son reconocidos o validados como tal, lo 
1. Fuerzas especiales de carabineros en conmemoración del 01 de mayo (Fuente: Archivo Fernández/Hermansen, 2008).
2. Feminista frente a la Catedral de Santiago en la conmemoración del 08 de marzo (Fuente: Archivo Fernández/Hermansen, 2008).
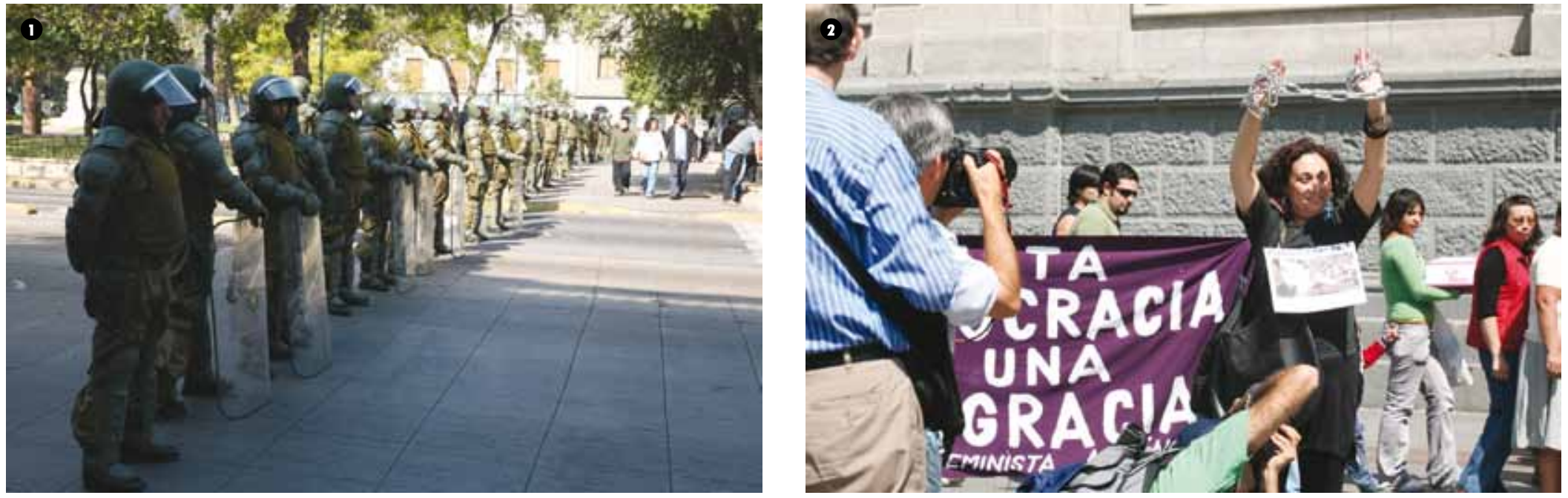

cual les impide aparecer en el espacio público tal como son. Y justamente las manifestaciones vendrían a ser un espacio que subvierte esa realidad. Sin embargo, lo que define a una manifestación es su carácter colectivo; los ciudadanos que se manifiestan aparecen en tanto pertenecientes $\mathrm{o}$ adscritos a una imagen o una pertenencia que los reúne como tal. «Para Arendt, el ejercicio de un derecho no es algo que un individuo realice. Tiene que ser un acción con otros, y debe ser pública. De hecho en sus propias palabras, tiene que entrar en la esfera de la apariencia» (Butler 2009 , p. 327). La acción de aparecer ante otros y en ese acto constituirse en ciudadanos entonces se basa en actuar juntos. Como señala Boria (2003), la ciudadanía es un estatus teórico que se adquiere en la práctica, o en otras palabras, el ciudadano se hace. «La ciudadanía es una conquista cotidiana. Las dinámicas segregadoras, excluyentes, existen y se renuevan permanentemente. La vida social urbana nos exige conquistar constantemente nuevos derechos o hacer reales los derechos que poseemos formalmente. El ciudadano lo es en tanto que ejerce de ciudadano, en tanto que es un ciudadano activo, partícipe de la conflictividad urbana» (Borja 2003, p 25). Manifestarse, aparecer ante otros con un objetivo político, supone entonces una alteración de las normas que regulan la vida pública, lo cual la mayor parte de las veces tiene un carácter conflictivo. Frecuentemente las manifestaciones se prohíben, se restringen o se reprimen, buscando limitar su impacto tanto político como urbano. A su vez muchas veces los manifestantes se resisten a esas limitaciones, ya sea de manera pacífica o violenta.

Las pugnas por la ocupación del espacio público para manifestarse permiten entonces destacar un elemento fundamental del espacio urbano contemporáneo: es un espacio en disputa. Como sostienen diversos autores (Borja, 2003; Borja y Muxí, 2003; Delgado, 2007), las manifestaciones en el espacio público visibilizan su carácter conflictivo, en tanto es en él donde se escenifican y representan las problemáticas no resueltas de la sociedad, la marginación social, cultural y política de diversos sectores sociales y el esfuerzo de éstos por hacer presentes y visibles, mostrando sus problemas, haciendo explícitas sus posturas e instalando sus puntos de vista, así como sus memorias y visiones sobre el pasado y el presente. Es decir, relevan al espacio público como lugar donde se produce y se ejerce la ciudadanía: «el lugar de la política de proximidad, de autogobierno, de las instituciones político-jurídicas y también de la autorrepresentación de la sociedad, de la expresión de las demandas colectivas, de las movilizaciones sociales, de los cambios en las relaciones de poder, de las innovaciones culturales y políticas. Es decir, la polis es el lugar del poder, de la participación y de la representación a través de las instituciones, y también de la oposición al poder y de los cambios en el poden» Borja y Muxí (2003, p. 107). Es el lugar del poder pero también del conflicto y de la resistencia, el espacio de las protestas y de las movilizaciones sociales. En este sentido, la pugna por el espacio público implica una tensión entre el resguardo del orden social y su alteración. Para Mouffe (2005), las concepciones actuales de lo político y del espacio público tienden a asentarse en una mirada consensualista, donde los conflictos sociales deben resolverse por la vía del diálogo y el acuerdo, lo que implica una anulación del conflicto. Al no existir condiciones para el acuerdo y el consenso, el conflicto se resuelve a través del ejercicio de la autoridad, expresada en control y represión del uso político de los espacios; lo que Tartakowsky (2010, p. 276) llama «pacificación del espacio público».

En términos concretos, esta pacificación del espacio público en el contexto nacional, y específicamente en las manifestaciones conmemorativas, se traduce en una importante presencia policial que muchas veces deriva en situaciones de acoso y represión por parte de carabineros. Tal como puede verse en la IMAGEN 1, obtenida en la conmemoración del 01 de mayo, el despliegue de efectivos de fuerzas especiales de carabineros es masivo e intimidatorio, y muchas veces apunta a un cierre de las vías de circulación, lo cual impide que las personas puedan desplazarse libremente, quedando expuestas a enfrentamientos y situaciones de violencia.

\section{DIFERENTES FORMAS DE MANIFESTARSE} EN EL ESPACIO PÚBLICO

Un primer elemento distintivo de las formas de manifestarse en las conmemoraciones 
3. Transformista frente al palacio presidencial en la marcha del orgullo gay (Fuente: Archivo Fernández/Hermansen, 2008).

4. Personas registrando a transformista frente a La Moneda en la marcha del orgullo gay (Fuente: Archivo Fernández/Hermansen, 2008).

5. Intervención de la Piedra de Pedro de Valdivia en el cerro Santa Lucía durante la marcha del 12 de octubre (Fuente: Archivo Fernández/Hermansen, 2008).
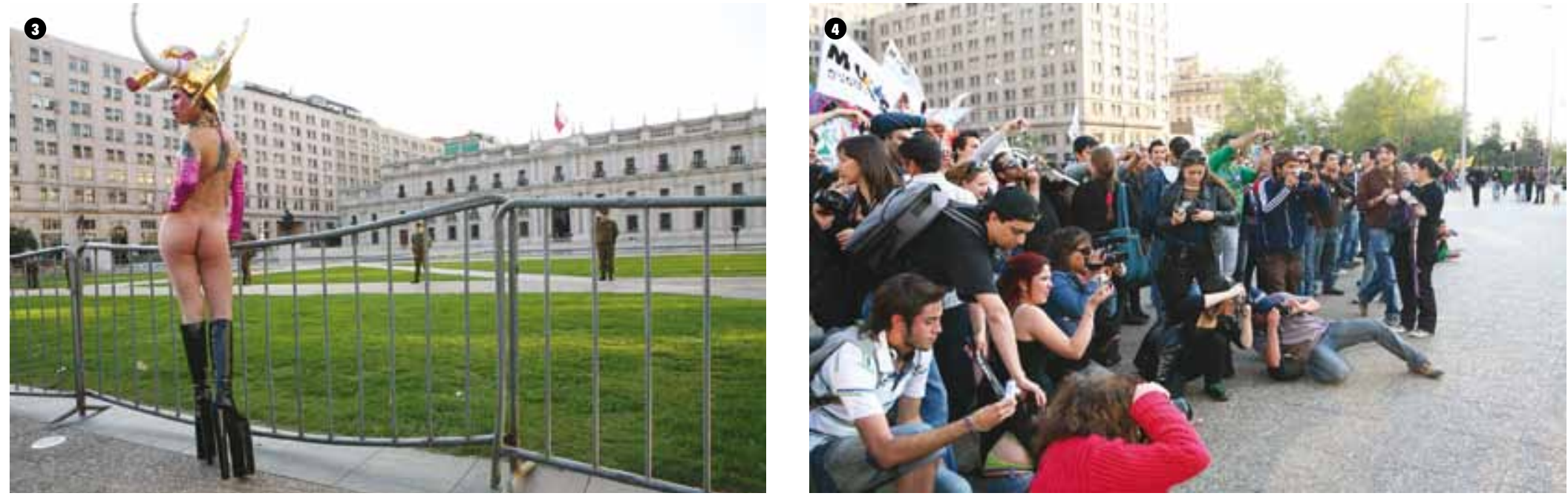

observadas, es el uso escénico de lugares simbólicamente relevantes. Los manifestantes suelen usar estos lugares para hacer algún tipo de demostración o intervención que problematiza el simbolismo propio del lugar elegido. Como señala Delgado (2007), toda manifestación supone una cierta cartografía o representación simbólica de la ciudad que convierte a ciertos lugares más relevantes que otros para manifestarse. Por ejemplo en la IMAGEN 2 puede apreciarse una situación ocurrida en la manifestación conmemorativa del Día Internacional de la Mujer (08 de marzo), donde una activista feminista se ubica frente a la catedral de Santiago con sus manos en alto enrolladas en cadenas que simbolizan la opresión histórica de las mujeres por parte de la iglesia católica. De fondo otras activistas llevan un lienzo donde está escrito «esta democracia es una desgracia».

Otro ejemplo es el de un transformista que en la marcha del orgullo gay posa frente a La Moneda. Tal como puede verse en la IMAGEN 3 , este transformista se apoya en las rejas que separan la calle de la Plaza de la Ciudadanía para ser fotografiado por los medios de prensa y en general por la gente que participa en la marcha, como puede apreciarse en la IMAGEN

4. Como escenario de la acción se encuentra La Moneda, resguardada por rejas y efectivos de carabineros. En este caso, la presencia del transformista pone en tensión el carácter tradicionalmente heterosexual y heteronormativo de los simbolismos asociados al Estado y la Nación.
En la IMAGEN 5 puede verse la intervención de la Piedra de Pedro Valdivia ocurrida en la marcha del 12 de octubre, donde las organizaciones mapuches expresan su rechazo a la conmemoración del descubrimiento de América. Esta Piedra se encuentra en un costado del cerro Santa Lucía, hacia la Alameda, y lleva inscrita un extracto de la carta que Pedro de Valdivia enviara a los reyes de España con ocasión del descubrimiento de Chile. En cada marcha del 12 de octubre, este lugar es intervenido por manifestantes, quienes la pintan de negro y escriben alguna consigna de protesta. En este caso la consigna es «katrileo, lemun, kariqueo: con su sangre se reconstruye la nación mapuche», en referencia a jóvenes mapuches asesinados en los últimos años en torno al conflicto por la recuperación de tierras en la Araucanía. Esta intervención no sólo interviene el simbolismo colonialista del lugar, sino que además lo utiliza como soporte de una inscripción que denuncia la violencia contra el pueblo mapuche y rinde homenaje a sus caídos.

Un segundo elemento que caracteriza a las manifestaciones conmemorativas es el uso de formas festivas de manifestación. Como señala Cruces (1998), los repertorios tradicionales de manifestación se han visto complementados por estrategias propias del arte, el carnaval y la fiesta urbana. En las IMÁGENES 6 y 7 pueden verse en la marcha del 01 de mayo y en la conmemoración del 08 de marzo, respectivamente, a manifestantes tocando instrumentos musicales, creando un ambiente

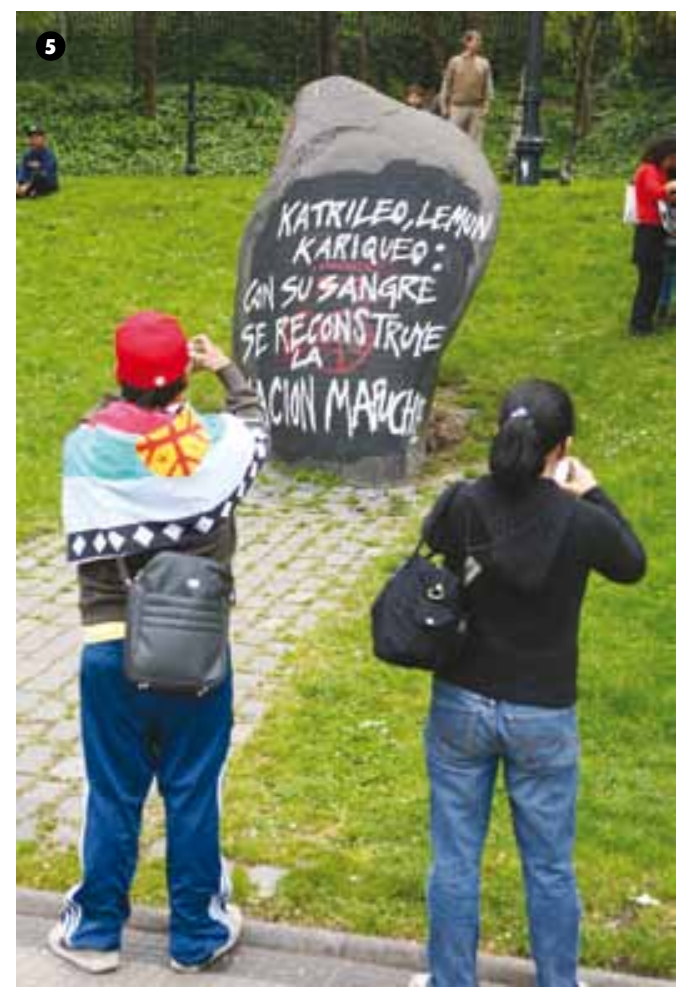

sonoro y visual que rompe los esquemas tradicionales de este tipo de manifestaciones.

En esta misma línea, en la IMAGEN 8 pueden verse bailarines de tinku durante la marcha del 01 de mayo, aunque estos bailarines suelen hacerse presente en diversas manifestaciones políticas, sobre todo las relativas al conflicto mapuche. El tinku es un baile andino que ha 
6. Grupo musical en la conmemoración del 01 de mayo (Fuente: Archivo Fernández/Hermansen, 2008).

7. Batucada de feministas lesbianas en la conmemoración del 08 de marzo (Fuente: Archivo Fernández/Hermansen, 2008).

8. Bailarines de Tinku en la conmemoración del 01 de mayo en la marcha del orgullo gay (Fuente: Archivo Fernández/Hermansen, 2008).

9. Travestis de la organización Amanda Jofré en la marcha del orgullo gay (Fuente: Archivo Fernández/Hermansen, 2008)
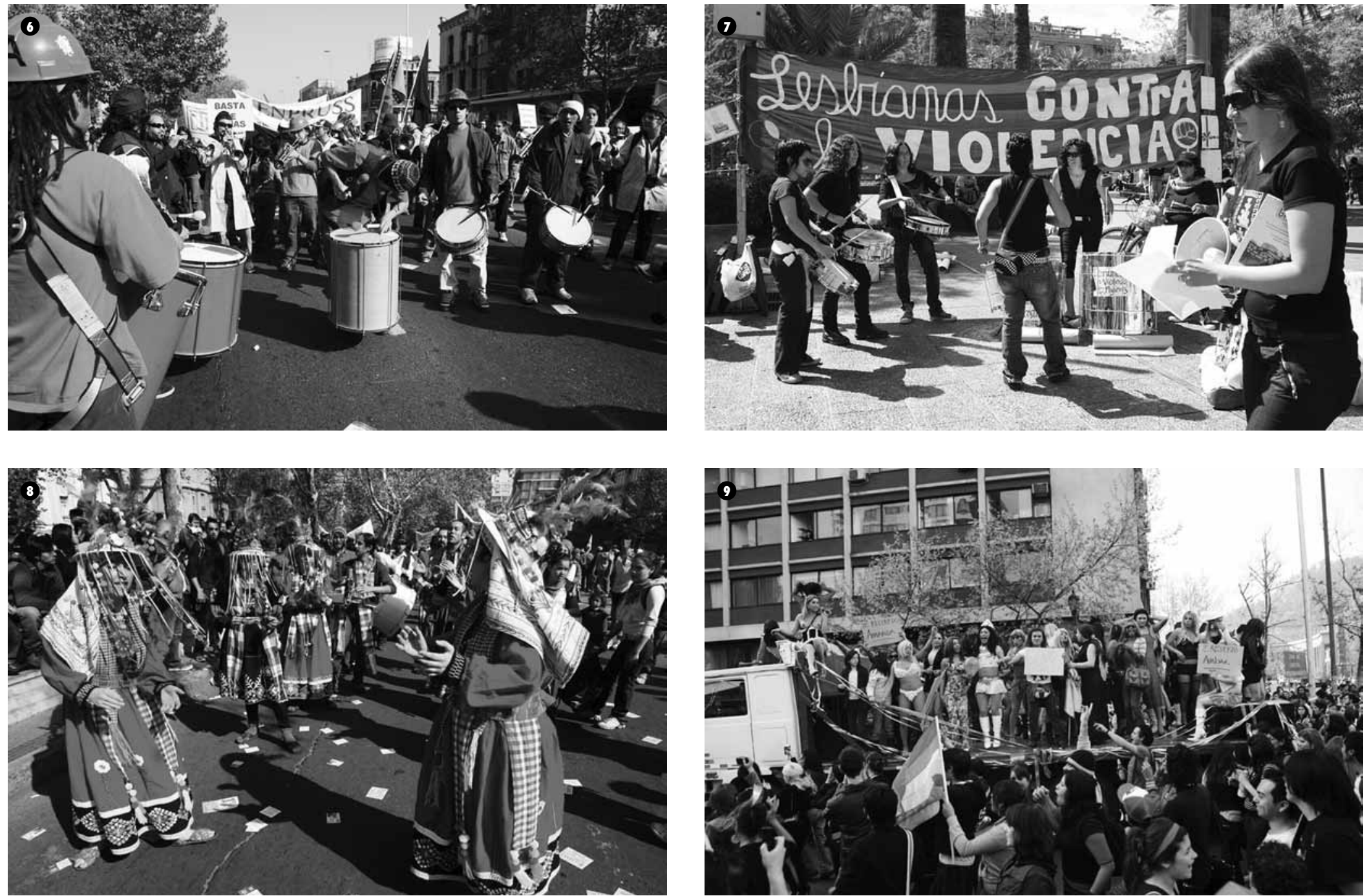

sido reapropiado en contextos urbanos como una forma de manifestarse políticamente a través de expresiones culturales que han sido tradicionalmente excluidas del espacio público (Fernández, 2011)

Otro ejemplo de apropiación festiva del espacio público es el que ocurre en la marcha gay, en la cual ha sido una tradición el uso de camiones para transportar manifestantes, pero sobre todo para animar el ambiente con personas que van bailando, haciendo discurso o bailando al ritmo de la música que emiten sistemas de amplificación colocado sobre los camiones. En la IMAGEN 9 puede verse el camión de la organización de travestis Amanda Jofré, sobre el cual van bailando y cantando los miembros de esta organización, siendo acompañados y vitoreados por una gran cantidad de manifestantes.

Finalmente, un tercer elemento distintivo de las formas de manifestarse en las conmemoraciones es el despliegue de un repertorio de acciones que van más allá de las tradicionalmente definidas como de protesta, como marchar, gritar consignas, llevar lienzos y banderas, etc. (Cruces, 1998). Este repertorio incluye acciones artísticas y culturales que buscan transmitir significados por medios no estrictamente textuales o explícitos. En la IMAgen 10 puede verse una acción artística o performance ocurrida en la conmemoración del 08 de marzo, donde una activista semidesnuda y con su cuerpo pintado vierte pintura roja a los pies de los carabineros de fuerzas especiales que vigilan la manifestación. Luego, la activista muestra fotografías de jóvenes asesinados por carabineros, lo cual puede interpretarse como una metáfora de la responsabilidad de esta institución en estas muertes.

Otro ejemplo es el juego de palín que realizan los manifestantes mapuches en la marcha del 12 de octubre. Como puede verse en la IMAGEN 11, los mapuches ocupan la Alameda frente al cerro Santa Lucía para esta actividad, como una forma de hacer visible no solamente sus demandas y requerimientos sino también sus expresiones culturales y deportivas. 
Finalmente, un último ejemplo es el de la performance realizada por los activistas de la Coordinadora Universitaria por la Disidencia Sexual CUDS, quienes en la marcha gay realizan una parodia de la candidatura de Zalaquett a la alcadía de Santiago, como puede verse en la IMAGEN 12. Vestidos con tenida semiformal, llevando un cartel con una foto de Jaime Guzmán donde está escrito «por una Jaime Guzmán homosexual», llevan un lienzo que interviene el nombre del candidato y propone la consigna "ganas por el ano».

\section{CONCLUSIONES: \\ HACIA LA CONSTRUCCIÓN DE UNA CIUDADANÍA RADICAL}

Si bien las conmemorativas aquí revisadas presentan importantes particularidades y diferencias respecto de otro tipo de manifestaciones, el análisis de las formas de manifestación que en ellas se desarrollan muestra una serie de prácticas que se encuentran en las manifestaciones del año 2011. En este sentido la comprensión de estas formas contribuye a un mejor entendimiento de la ocupación política de la ciudad y de sus espacios públicos.

Asimismo, el análisis realizado aquí pone en evidencia que nos encontramos frente a expresiones ciudadanas que van más allá de la mera presencia en el espacio público para hacer reivindicaciones o expresar un cierto descontento. Hoy día la manifestación en el espacio público parece inscribirse en una forma de constitución de ciudadanía donde la aparición ante otros se caracteriza por mostrarse tal como se quiere, ya sea con el cuerpo pintado, vestido, travestido o prácticamente desnudo, con atuendos y ropas propios de la cultura con la cual los manifestantes se identifican. En este sentido, los lugares que se ocupan, las formas festivas de manifestarse y el uso de estrategias artísticas y culturales parecen orientadas tanto a hacer visible lo que los manifestantes piden o por lo cual protestan, como lo que son y cómo quieren ser vistos. Francisco Cruces define esta dimensión de la manifestación política relativa al derecho al reconocimiento como «dignidad en acción» (Cruces 1998, p. 76), pero esta definición puede resultar algo limitada en la medida que no
10. Intervención en la conmemoración del 08 de marzo (Fuente: Archivo Fernández/Hermansen, 2008)

11. Juego de palín en la marcha del 12 de octubre (Fuente: Archivo Fernández/Hermansen, 2008).

12. Intervención de la CUDS en la marcha del orgullo gay (Fuente: Archivo Fernández/Hermansen, 2008).
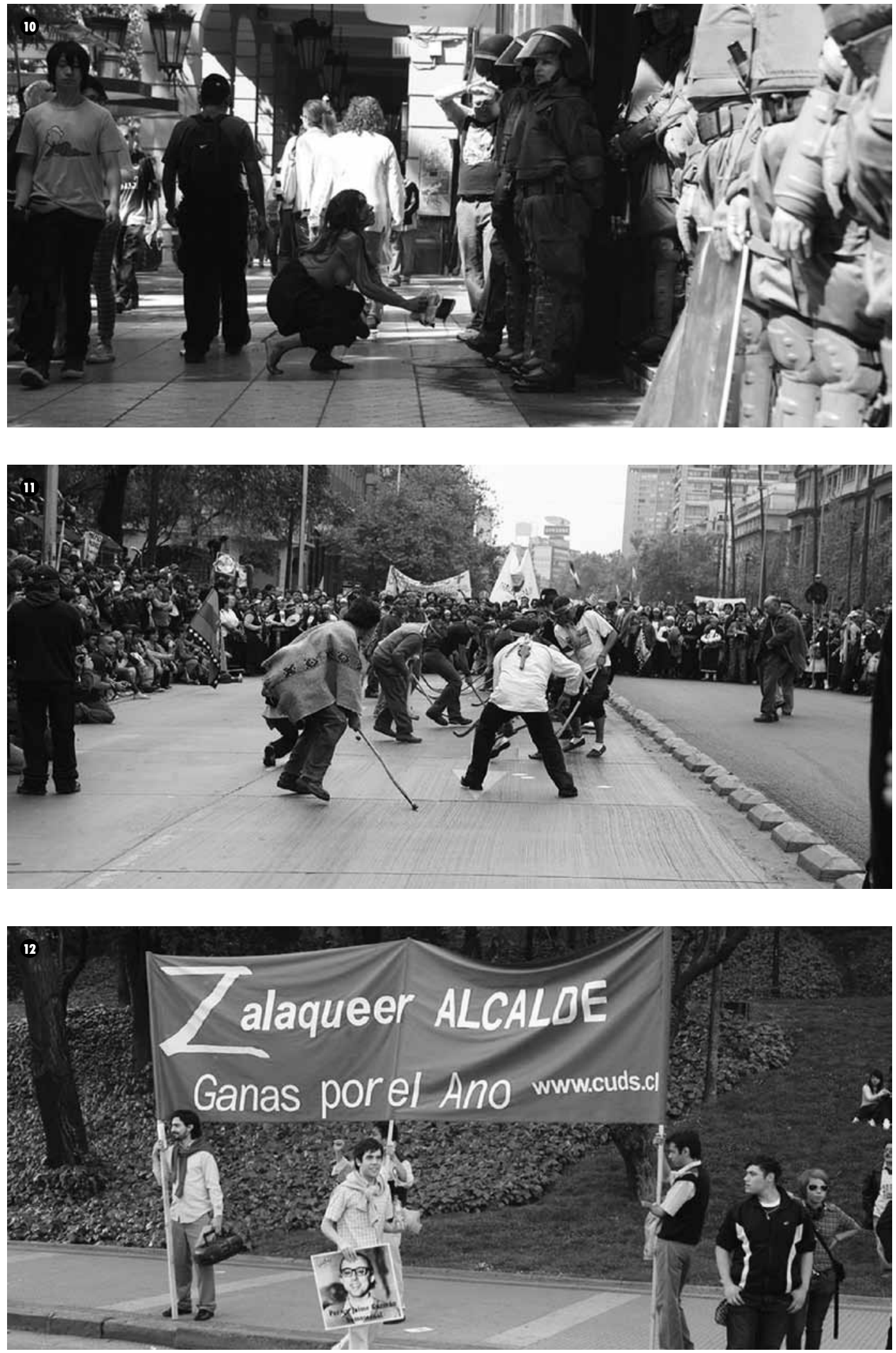
realza un elemento fundamental de la búsqueda de reconocimiento: el orgullo de ser quien se es.

Mouffe (2005) propone la idea de democracia radical para referirse a un modo de convivencia social que le dé cabida a la pluralidad y al conflicto. Desde esta perspectiva, una democracia radical requiere una ciudadanía radical, que busca reconocimiento desde el orgullo de ser quien se es, y podemos pensar que ésta es la ciudadanía que se ha venido constituyendo en los últimos años en diferentes espacios de participación, donde tal como se ha propuesto aquí, las manifestaciones conmemorativas han sido instancias fundamentales para la construcción y avance de esta ciudadanía.

\section{BIBLIOGRAFÍA}

Arendt, H. La condición humana. Buenos Aires: Paidós Estado y Sociedad, 2005.
Boria, J. La ciudad conquistada. Madrid: Alianza, 2003.

Borja, J; Muxí, Z. El espacio público: ciudady ciudadanía. Madrid: Alianza Editorial, 2003.

Butler, J. «Performatividad, precariedad y políticas sexuales». AlBR, Revista de Antropología Iberoamericana 2009; 4(3):321-36.

Cruces, F. «El ritual de la protesta en las marchas urbanas». En: García Canclini, N. Cultura y comunicación en Ciudad de México. México DF: Grijalbo, 1998; 27-83.

Delgado, M. Sociedades movedizas. Pasos hacia una antropología de las calles. Barcelona: Anagrama, 2007.

Fernández, F. Festividad y ritualidad andina en la Región Metropolitana. Santiago de Chile: Ocho Libros Editores, 2011.

Fernández, R; Hermansen, P. Aproximaciones metodológicas para una sociología visual a partir del estudio de prácticas de memoria colectiva en el espacio público de la ciudad de Santiago. Venezuela: Espacio Abierto,
Asociación Venezolana de Sociología, 2009; 18(3):445-60.

Gil Calvo, E. «La ocupación del espacio público». Diario El País 25-12-2011 [en: http://www.elpais.com/articulo/ opinion/ocupacion/espacio/publico/ elpepiopi/20110921 elpepiopi_4/Tes].

Mouffe, Ch. «Política y pasiones: las apuestas de la democracia». En: Arfuch, L. Pensar este tiempo. Espacios, afectos, pertenencias. Buenos Aires: Paidós, 2005.

Roitman, M. «Los indignados: el retorno de la política». Diario La Vanguardia 25-122011 [en: http://www.vanguardia.com.mx/ losindignadoselretornodelapolitica1 108798.html].

Tartakowsky, D. Manifester a Paris. París: Champ Vallon, 2010. 